Disponível em:

http://editora.unoesc.edu.br/index.php/race

Race, Joaçaba, v. 14, n. 2, p. 505-536, maio/ago. 2015

\title{
CENTROS DE SERVIÇOS COMPARTILHADOS: UM ESTUDO DE CASO SOBRE FATORES INTERVENIENTES NA FORMAÇÃO DE COMPETÊNCIAS GERENCIAIS
}

\section{Shared Services Centers: a case study about the intervening factors on Managerial Competencies building}

Murilo Rodrigues dos Santos

E-mail: murilors@gmail.com

Mestre em Administração de Empresas pela Pontifícia Universidade Católica do Rio de Janeiro; Graduado em Administração pela Universidade Federal do Rio de Janeiro; Administrador Pleno em empresa do setor de energia integrada; Tutor Presencial na Universidade Federal Fluminense.

Sandra Regina da Rocha-Pinto

E-mail: sanpin@iag.puc-rio.br

Doutora em Ciências Humanas - Educação - pela Pontifícia Universidade Católica do Rio de Janeiro; Mestre em Administração de Empresas pela Pontifícia Universidade Católica do Rio de Janeiro; Professora assistente do Instituto de Administra-

ção e Gerência da Pontifícia Universidade Católica do Rio de Janeiro. Endereço para contato: Rua Marquês de São Vicente, 225, Gávea, 22451-900, Rio de Janeiro, Rio de Janeiro, Brasil.

\section{Maria Isabel Peixoto Guimarães}

E-mail: belguimaraes@uol.com.br

Mestre em Engenharia de Produção pelo Instituto Alberto Luiz Coimbra de Pós-graduação e Pesquisa em Engenharia; doutoranda em Administração de empresas pela Pontifícia Universidade Católica do Rio de Janeiro; Professora da disciplina Capital Humano no Master on Business and knowledge Management do Coppe da Universidade Federal do Rio de Janeiro. 
Resumo

Este estudo de caso, de natureza qualitativa, objetivou investigar os fatores intervenientes na formação de competências gerenciais. Para tanto, foram entrevistados 14 empregados participantes do Programa de Desenvolvimento Gerencial para potenciais gestores da Unidade de Serviços Compartilhados de uma empresa brasileira atuante no ramo de energia integrada. Os resultados apontaram que os fatores intervenientes derivam de três categorias inter-relacionadas: o Conceito de Unidade de Serviços Compartilhados as Competências Gerenciais Requeridas e o Processo de Formação das Competências Requeridas. Para a formação de Competências Gerenciais, foram valorizadas as atividades práticas e vivenciais, o papel dos gerentes atuais e a necessidade de avaliação e feedback.

Palavras-chave: Competências. Desenvolvimento gerencial. Centros de Serviços Compartilhados. Formação de competências.

\title{
Shared Services Centers: a case study about the intervening factors on Managerial Competencies building
}

\begin{abstract}
This qualitative case study aimed to investigate the intervening factors on managerial competencies building. For that purpose, interviews were conducted with 14 employees of a Brazilian company from the integrated energy business. The participants were attending a Manager Development Program for prospective managers at the Shared Services Unit. The results demonstrated that the intervening factors derive from three interrelated categories: the Concept of the Shared Services Unit, the Required Managerial Competencies and the Required Competencies Building Process. For the Managerial Competencies building, it was remarked the practical and experiential activities, the role of current managers and the need of assessment and feedback.
\end{abstract}

Keywords: Competencies. Managerial development. Shared Services Centers. Competencies building.

\section{INTRODUÇÃO}

As organizações vêm se modificando ao longo do tempo e os esforços para atingir seus objetivos são constantes. Para que esses esforços sejam bem direcionados, é importante a definição de quais são as competências necessárias para que as empresas sejam bem-sucedidas no mercado (ROCHA; SALLES, 2005), o que não é tarefa muito simples, uma vez que as companhias apresentam diversos tipos de estruturas organizacionais e, em cada unidade, pode haver realidades e estruturas distintas que buscam se complementar. Assim, supõe-se que diferentes unidades de uma empresa podem demandar diferentes formas de gestão e, consequentemente, diferentes competências.

Entre os diversos tipos de estruturas de unidades existentes nas organizações, há uma forma de organização conhecida como serviços compartilhados, também 
denominada, em inglês, shared services, que tem sido adotada em diversos tipos de empresas. Quinn, Cooke e Kris (2000) definiram esses centros como a prática na qual as organizações compartilham um conjunto de serviços em vez de tê-los como uma série de funções de apoio duplicadas. Os Centros de Serviços Compartilhados (CSCs) concentram processos administrativos e de suporte não estratégicos para a atividadefim da empresa. Ou seja, Centros de Serviços Compartilhados (CSCs) são unidades internas de uma organização que prestam serviços para outras áreas da Companhia.

Considerando as características e os objetivos específicos dos CSCs, podese supor que exista a necessidade do desenvolvimento de competências gerenciais específicas para a sua gestão. Em decorrência dessa suposição, o principal objetivo deste estudo foi investigar os fatores intervenientes na formação de competências gerenciais na Unidade de Serviços Compartilhados da empresa objeto desta pesquisa.

Entende-se que a análise da formação de competências é importante em todos os níveis de ensino e aprendizagem. Porém, este trabalho está restrito ao Programa de Desenvolvimento Gerencial para futuros gestores da empresa estudada. A pesquisa de campo foi conduzida na perspectiva dos indivíduos em processo de desenvolvimento nesse Programa, com o objetivo de identificar a percepção desses sujeitos sobre as competências gerenciais desejáveis, a forma que essas competências podem ser desenvolvidas, bem como os facilitadores e os entraves organizacionais que podem influenciar nesse desenvolvimento. Foi possível captar as representações, os sentimentos e os entendimentos desses indivíduos, e realizar análises sobre o que esse grupo pensa acerca de competências de gestão focadas em Unidades de Serviços Compartilhados.

Julga-se que este estudo de caso poderá auxiliar na compreensão da prática da administração e da gestão de competências, tendo como principal reflexão a formação de competências de gestão. Poderá, também, trazer uma relevante contribuição teórica, ao desvelar fatores que colaboram para a formação de gestores alinhados com as demandas organizacionais específicas para os Centros de Serviços Compartilhados, uma vez que o estudo foca na percepção dos futuros gestores dessas unidades e não foram encontrados estudos significativos com essa especificidade.

Este artigo está organizado em cinco seções, incluindo: a primeira, esta introdução; a segunda, que apresenta a moldura teórica; a terceira, que descreve os procedimentos metodológicos empregados; a quarta, que apresenta a análise e a discussão dos resultados; e, por fim, a quinta, que apresenta a conclusão. 


\section{REFERENCIAL TEÓRICO}

Este tópico encontra-se organizado em quatro seções: Centro de Serviços Compartilhados, A Função Gerencial, Competências Gerenciais e Formação de Competências.

\section{1 CENTRO DE SERVIÇOS COMPARTILHADOS (CSCS)}

Empresas de grande porte estão implantando os Centros de Serviços Compartilhados (CSCs) como uma estratégia de padronização, melhoria de processos internos, agilidade e redução de custos. Bergeron (2003) define CSCs como uma estratégia colaborativa, na qual um conjunto de funções do negócio é concentrado em uma nova e semiautônoma unidade de negócio. Essa unidade possui uma estrutura gerencial criada de forma a promover a eficiência, a geração de valores, economias de custo e melhores serviços aos clientes internos da corporação, como um negócio competindo no mercado, que possui seu próprio orçamento e deve arcar com a responsabilidade de seu gerenciamento.

Segundo Schulman et al. (2001), CSCs podem ser definidos como a concentração dos recursos da organização realizados como atividades tipicamente espalhadas, de forma a servir a múltiplas partes internas com custos reduzidos e alta qualidade na prestação dos serviços, com a meta de atender aos clientes finais e aumentar o valor da corporação. E esses serviços deveriam funcionar em uma organização em separado, seguindo, principalmente, os seguintes atributos: ser uma organização stand-alone; ser orientada por processos e focada em suas atividades específicas; ser dirigida pela competitividade do mercado, focada na alavancagem tecnológica e melhoria contínua; e ser uma organização que prioriza seus "parceiros internos", as unidades de negócio. Shah (1998) atenta que os CSCs são uma unidade orientada para as necessidades de seus clientes internos, buscando qualidade e maximização da utilização de recursos, e não devem ser vistos como uma mera centralização de atividades de apoio realizadas sem identificar qual é a real necessidade de determinada área. Entretanto, de acordo com Kaplan (2000), na prática, alguns CSCs podem se tornar burocráticos, insensíveis e inflexíveis e não proporcionar os almejados benefícios econômicos às unidades operacionais. 


\section{2 A FUNÇÃO GERENCIAL}

A função gerencial é complexa e diversificada e, conforme Manfredini (2007), existe concordância entre a maioria dos autores quanto à atribuição de algumas funções básicas aos gerentes, como dirigir, organizar e controlar pessoas ou grupos de pessoas. Por sua vez, o termo gerenciamento foi descrito na antiguidade, ainda que de maneira arcaica, e as grandes construções históricas, como as Pirâmides do Egito, a Muralha da China e os diversos castelos, já apresentavam uma forma rudimentar de definição de alguém responsável por distribuir os afazeres, delegar ordens, estabelecer prioridades e fornecer os materiais (ROBBINS; COULTER, 1998). Esses autores ensinam que, no século XVIII, com o advento da Revolução Industrial, surgiu um novo conceito de administrar, no qual a referência gerencial se concentrava no dono do negócio, com forte centralização de poderes. Entretanto, com o crescimento das empresas, instituiuse a utilização de estruturas hierárquicas e especializações de funções, o que levou ao surgimento da figura do profissional gerente assalariado.

Para Mattos (1985), a eficácia do gestor está em conseguir que seus subordinados atinjam os resultados esperados por ele com o mínimo de resistência possível e o máximo de aproveitamento de seu potencial. Crosby (1991) assevera que o gerente deve ter papel estrategista, sendo capaz de perceber o presente e o futuro, proporcionando trabalho de qualidade por meio da participação e compreensão de sua equipe. Assim, é necessário que, ao colocar em prática algum projeto estabelecido pela cúpula, realize-o com o máximo de visão e criatividade, permitindo que a equipe de trabalho se engaje na busca do alcance das metas e dos resultados esperados.

Em contraponto à visão clássica da função gerencial - planejar, organizar, dirigir e controlar -, Land e Silva (2011) indicam a necessidade de uma prática gerencial alinhada à teoria da complexidade e aos desafios do século XXI, que inclui as funções de monitoramento das informações do ambiente, delimitação de estratégias, fortalecimento das relações interpessoais e incentivo e viabilização da aprendizagem dos colaboradores da organização.

Outra visão, complementar, sobre a prática gerencial, aponta a necessidade de que gestores adotem uma abordagem de gestão participativa e bottom-up, com o objetivo de criar espaços organizacionais favoráveis às mudanças emergentes, à criatividade e à criação de conhecimento (MAIMONE; SINCLAIR, 2014). De forma alinhada a essa visão, Ellström e Ellström (2014) demonstraram empiricamente a 
importância dos gestores para os resultados dos treinamentos realizados por suas equipes, caracterizando-os como apoiadores ou não apoiadores.

Pelo conjunto de funções que os gestores acumulam, eles são considerados um recurso-chave quando se analisam as organizações sob o olhar da visão baseada em recursos e, por isso, devem desempenhar suas funções de maneira eficiente e eficaz (SHEEHAN, 2012).

\subsection{COMPETÊNCIAS GERENCIAIS}

Para desempenhar a complexa função gerencial descrita na seção 2.2, o gestor deve dispor de um conjunto de competências gerenciais. A competência pode ser percebida como um estoque de recursos (conjunto de conhecimentos, habilidades e atitudes) que o indivíduo detém (FLEURY; FLEURY, 2004). Existem diversas correntes que buscam uma definição apropriada para as competências. Para ilustrar a ênfase das principais correntes teóricas relacionadas à noção de competência gerencial, Streit (2001) realizou a síntese apresentada no Quadro 1:

Quadro 1 - Principais conceitos de competência gerencial

\begin{tabular}{|l|l|l|}
\hline Autores & Conceito & Ênfase \\
\hline $\begin{array}{l}\text { Le Boterf } \\
(1999, \text { p. } \\
109) .\end{array}$ & $\begin{array}{l}\text { Saber mobilizar e combinar os recursos pesso- } \\
\text { ais (conhecimentos, habilidades, atitudes) e os } \\
\text { recursos do seu ambiente, de maneira pertinente, } \\
\text { em uma situação específica. }\end{array}$ & $\begin{array}{l}\text { Combinação de } \\
\text { recursos para a } \\
\text { ação em contextos } \\
\text { variados. }\end{array}$ \\
\hline $\begin{array}{l}\text { Fleury e } \\
\text { Fleury (2004, } \\
\text { p. 30). }\end{array}$ & $\begin{array}{l}\text { Um saber agir responsável e reconhecido, que im- } \\
\text { plica mobilizar, integrar, transferir conhecimentos, } \\
\text { recursos, habilidades, que agreguem valor econô- } \\
\text { mico à organização e valor social ao indivíduo. }\end{array}$ & $\begin{array}{l}\text { Agregação de valor } \\
\text { econômico e social. }\end{array}$ \\
\hline $\begin{array}{l}\text { Parry (1998, } \\
\text { p. 60). }\end{array}$ & $\begin{array}{l}\text { Cluster de conhecimentos, atitudes e habilidades } \\
\text { relacionadas que influem na realização de uma } \\
\text { atividade. }\end{array}$ & $\begin{array}{l}\text { Performance no } \\
\text { trabalho. }\end{array}$ \\
\hline $\begin{array}{l}\text { Zarifian } \\
(2001, \text { p. 68). }\end{array}$ & $\begin{array}{l}\text { A competência é "o tomar iniciativa" e "o assumir } \\
\text { responsabilidade" do indivíduo diante de situa- } \\
\text { çôes profissionais com as quais se depara. }\end{array}$ & $\begin{array}{l}\text { Entendimento } \\
\text { prático de situações } \\
\text { complexas. }\end{array}$ \\
\hline
\end{tabular}

Fonte: Streit (2001).

De acordo com Ruas (2005), as competências gerenciais conseguem conectar os projetos organizacionais aos individuais, pois, conforme Zarifian (2001), mobilizam conhecimentos, habilidades e atitudes pessoais para cumprir certa tarefa ou responsabilidade, em determinada situação. Ainda segundo Ruas (2005), o recurso de atributos (saber ser/agir) pode dividir-se em profissional e pessoal e os recursos 
de habilidade (saber fazer) envolvem o aprendizado pela experiência profissional. Por sua vez, Mintzberg (1973) propôs oito habilidades gerenciais: relacionamento com colegas; resolução de conflitos; comunicação e processamento de informações; tomada de decisões em condições de ambiguidade; alocação de recursos; habilidades empresariais; introspecção; e liderança.

Por outro lado, para Cockerill (1994), os gerentes precisam continuamente reunir novas informações, formar ideias sobre o cenário atual, avaliando diversas opções que possam eventualmente emergir. $\mathrm{O}$ autor utiliza em suas pesquisas 11 competências de alto desempenho gerencial: pesquisa da informação; formação dos conceitos; flexibilidade conceitual; busca interpessoal; interação gerencial; orientação no sentido do desenvolvimento; impacto; autoconfiança; apresentação; orientação proativa; e orientação para a realização.

Como uma possibilidade de agrupamento das competências gerenciais, Motta (2002) propõe quatro tipos de habilidades necessárias aos gestores: cognitiva, que possibilita a categorização de problemas administrativos e a compreensão do particular por meio do conhecimento geral; analítica, que permite avaliar a utilidade e o potencial das técnicas administrativas; comportamental, que habilita o gestor a se comportar de forma diversa da anteriormente acostumada; e de ação, que se delineia por desenvolver a capacidade de inferência.

Já Cooper, Basson e Schaap (2006) apontaram a importância do desenvolvimento de algumas características individuais para o futuro mundo do trabalho - que é possível assumir que seja o mundo de hoje: “[...] paixão por mudança, orientação para oportunidade, confiança, integridade, bondade e amor, motivação e paixão por aprender." (COOPER; BASSON; SCHAAP 2006, p. 471, tradução nossa). Essas características, que vão além das competências técnicas, devem ser consideradas como um conjunto de atitudes, importante dimensão do conceito de competência. A esse grupo, podem-se incorporar as competências relacionadas às inteligências emocional e social (BOYATZIS, 2011; THORY, 2013), ou as soft skills (JAIN; ANJUMAN, 2013; CHROBOT-MASON; LESLIE, 2012), como, por exemplo, autocontrole, empatia, diplomacia e gerenciamento de equipes multiculturais.

Ao apresentar as competências necessárias ao exercício das funções gerenciais alinhadas ao pensamento complexo, Land e Silva (2011) destacam cinco capacidades que devem fazer parte do conjunto de competências gerenciais: capacidade de criar um ambiente adequado; capacidade de estimular a cooperação; capacidade de interagir e fortalecer canais de comunicação; capacidade de promover agregação em torno de um objetivo global; e capacidade de incentivar o aprendizado 
contínuo. Por sua vez, Closs e Antonello (2014) relacionam a necessidade de novas aprendizagens percebidas por gestores, que surgem a partir de diferentes aspectos do contexto contemporâneo, demonstrando um amplo espectro de competências necessárias à gestão contemporânea. O Quadro 2 ilustra os achados das autoras.

Quadro 2 - Transformações contemporâneas e implicações em aprendizagem

\begin{tabular}{|l|l|}
\hline $\begin{array}{l}\text { Aspectos da Contempora- } \\
\text { neidade }\end{array}$ & Necessidades de aprendizagem \\
\hline Globalização & $\begin{array}{l}\text { Domínio do idioma Inglês; entendimento e aceitação de } \\
\text { outros valores; compreensão de semelhanças e diferenças } \\
\text { organizacionais em contextos culturais distintos; necessi- } \\
\text { dade de estar conectado a outros mercados; necessidade de } \\
\text { desenvolvimento de novos arranjos familiares. }\end{array}$ \\
\hline $\begin{array}{l}\text { Transformações políticas, } \\
\text { Brasil }\end{array}$ & $\begin{array}{l}\text { Conhecimento de novas técnicas e modismos gerenciais, } \\
\text { incorporados aos seus discursos e às suas práticas geren- } \\
\text { ciais; adaptação a novas situações profissionais, com aquisi- } \\
\text { ção contínua de novos conhecimentos; autoconhecimento, } \\
\text { oriundo de reflexões sobre potencialidades e limitações } \\
\text { para atuar em diferentes posições profissionais; criação e } \\
\text { síntese de novas ideias e habilidades demandadas por uma } \\
\text { sociedade complexa e em rápida mudança. }\end{array}$ \\
\hline Novas tecnologias & $\begin{array}{l}\text { Filtragem e priorização de informações; estabelecimento de } \\
\text { limites entre a vida pessoal e a profissional; necessidade de } \\
\text { identificação constante de ameaças e oportunidades ligadas } \\
\text { ao uso de novas tecnologias, bem como de se adaptar a } \\
\text { uma "nova lógica", dosando o uso de novas tecnologias } \\
\text { tanto no acesso a informações quanto na comunicação } \\
\text { interpessoal. }\end{array}$ \\
\hline Incerteza & $\begin{array}{l}\text { Lidar com desafios, pressões e responsabilidades crescentes } \\
\text { para se manterem em seus cargos, crescerem na carreira } \\
\text { e acumularem recursos para um futuro sem garantias; } \\
\text { não transmitir indecisão, tomando decisões rapidamente, } \\
\text { confiando mais em processos intuitivos, capazes de integrar } \\
\text { saberes armazenados decorrentes de experiências e aprendi- } \\
\text { zagens anteriores, apropriados para atuarem quando existem } \\
\text { poucos precedentes ou várias alternativas plausíveis de solu- } \\
\text { ção para determinada situação (KHATRI; NG, 2000). }\end{array}$ \\
$\begin{array}{l}\text { Capacidade de adaptação; acúmulo de atividades e maior } \\
\text { dispêndio de energia; gerenciamento de várias coisas ao } \\
\text { mesmo tempo; desenvolvimento de networks; conciliação do } \\
\text { tempo entre as atividades profissionais e pessoais/familiares. }\end{array}$ \\
\hline ano(s)
\end{tabular}

Fonte: adaptado de Closs e Antonello (2014, p. 158-159).

Godoy e D’Amelio (2012) perceberam, em estudo empírico, a necessidade do desenvolvimento da metacompetência "aprender a aprender" para que os gestores pudessem desenvolver outras competências. Tal resultado, como sugerem as autoras, estão 
em consonância com a ideia de Le Boterf (2003) de que os profissionais devem transformar sua prática profissional em oportunidade de criação de saber, a partir da experiência.

\section{4. FORMAÇÃO DE COMPETÊNCIAS}

Em razão da grande complexidade do atual ambiente de negócios, as metodologias empregadas em cursos de especialização, voltados para a formação gerencial, parecem não estar adequadas às necessidades organizacionais (ANTONELLO; RUAS, 2005). Por isso, um grupo significativo de pesquisadores vem estudando diferentes formas de desenvolvimento de competências gerenciais dentro das próprias empresas. Alguns serão apresentados nesta seção.

O desenvolvimento de competências dos indivíduos pode ser considerado um processo de aprendizagem, o qual, segundo Fleury e Fleury (2004), pode ser pensado como um processo de mudança, provocado por diversos estímulos, mediado por emoções, que pode vir ou não a explicitar mudança no comportamento de uma pessoa. Segundo Abbad e Borges-Andrade (2004), o conceito de aprendizagem relaciona-se à aquisição, à retenção, à generalização e à transferência de conhecimentos. Entretanto, a relação entre desenvolvimento de competência e processos de formação e treinamentos convencionais (comumente utilizados pelas empresas) tende a gerar um gap, uma vez que nem sempre se concretizam as expectativas de desenvolver competências de forma quase "automática" entre os egressos desses cursos convencionais (RUAS; COMINI, 2007).

Le Boterf (1999) afirma que diferentes profissionais, ainda que tenham os mesmos interesses, constroem trilhas distintas para o seu desenvolvimento, conforme ilustrado na Figura 1, na qual se pode perceber que, para atingir a competência desejada (objetivo ou ponto de chegada), o Profissional A percorreu uma trajetória de desenvolvimento diferente daquela do Profissional B, cada qual se valendo de diferentes soluções de aprendizagem. E, como aprender faz nascer novas necessidades, cada ponto de chegada representa um novo ponto de partida. 
Figura 1 - Trilhas de aprendizagem

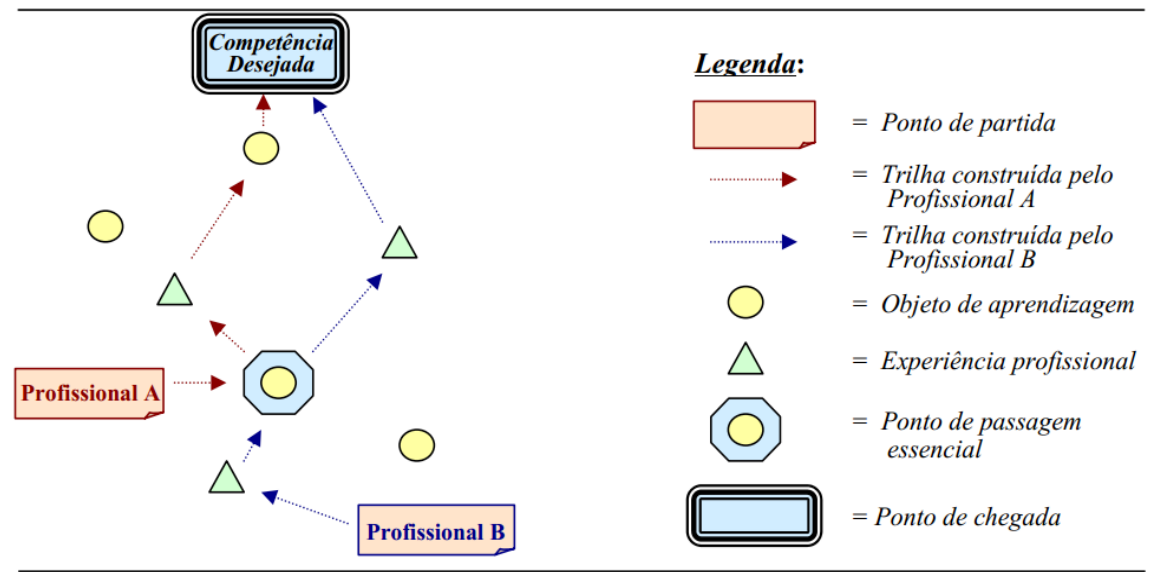

Fonte: adaptada de Le Boterf (1999).

Le Boterf (1999) apresenta o conceito de navegação profissional para explicitar o processo de aquisição de novas aprendizagens e de profissionalização ao longo da vida. Esse processo possui pressupostos, como o ato voluntário da aprendizagem, as definições do ponto de partida e de chegada e as competências que se desejam adquirir. Ou seja, constitui um "mapa de oportunidades” colocado à disposição dos navegadores, não limitado a situações de treinamento, que pode ser devidamente acompanhado pelas partes interessadas (LE BOTERF, 1999).

Dutra (2008) reforça que o desenvolvimento das pessoas pode ser dividido em duas categorias: ações formais e não formais de desenvolvimento. As ações de desenvolvimento formais são aquelas estruturadas por meio de conteúdo programático específico, envolvem metodologias didáticas, instrutores ou orientadores, materiais bibliográficos e uma agenda de trabalho ou aulas. Por outro lado, as ações de desenvolvimento não formais são estruturadas por meio de atuações no próprio trabalho ou de situações ligadas à atuação do profissional e podem ser concebidas de diferentes formas, mas sempre envolvem o profissional em desenvolvimento.

Em complemento, Antonello (2007) destaca que o desenvolvimento de competências gerenciais pode se basear em diferentes tipos de processos de aprendizagem: formal; informal; incidental; baseada no trabalho; autodirigida, da vida, pelo autodesenvolvimento. Independentemente da forma como ocorre, qualquer processo de aprendizagem cria a oportunidade de se vivenciar algum tipo de situação ou problema, que implica uma ação envolvida por uma reflexão. Essa experiência, 
acompanhada de uma ação com reflexão, chamada de aprendizagem experiencial, é que levará ao desenvolvimento de competências (ANTONELLO, 2007).

O Esquema 1 ilustra o papel da aprendizagem na ação no desenvolvimento de competências.

Esquema 1 - O papel da aprendizagem na ação no desenvolvimento de competências

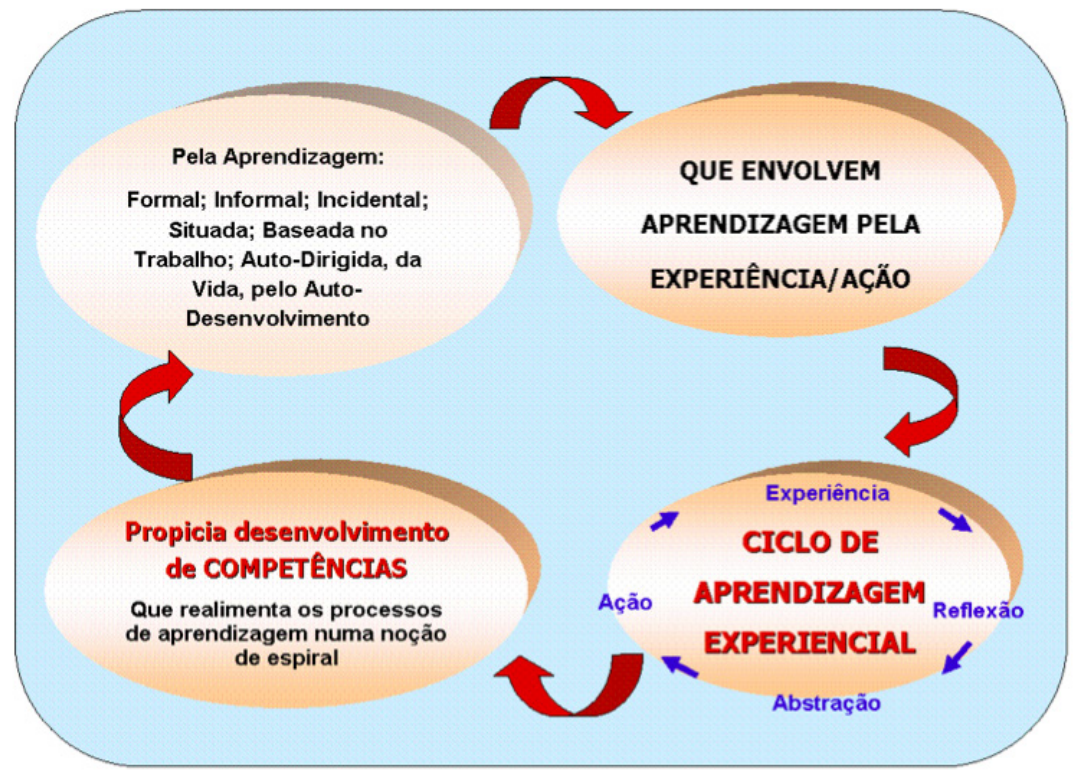

Fonte: Antonello (2007).

Em trabalho anterior, Antonello (2004) já havia identificado, de forma mais abrangente e complementar ao Esquema 1, 12 formas de aprendizagem que contribuem para o desenvolvimento de competências gerenciais, a saber: experiência anterior e transferência extraprofissional; experienciar; reflexão; autoanálise (autoconhecimento); observação (modelos); feedback; mudança de perspectiva; mentoria (mentoring) e tutoria (coaching); interação e colaboração (em grupo); treinamentos; informal e aprendizagem pela articulação entre teoria e prática. Ainda segundo Antonello (2007), alguns elementos exercem papel fundamental no processo de aprendizagem experiencial: autonomia, motivação, interação e intencionalidade do indivíduo em aprender.

Por sua vez, Cheetham e Chivers (2001) discorreram sobre a aprendizagem informal e elencaram os principais métodos para o desenvolvimento: prática e repetição, reflexão, observação e cópia, avaliação, transferência de ocupações extraprofissionais, 
atividades de mais esforço ou tensão, mudança/alteração de perspectiva, mentoring, absorção inconsciente, uso de dispositivos mentais, articulação e colaboração.

Ouweneel et al. (2009) confirmaram, em estudo empírico, que gestores que desempenham tarefas com maior demanda psicológica e maior oportunidade de controle aprendem mais informalmente no local de trabalho do que gestores com outro tipo de trabalho.

Ademais, de acordo com Dutra (2008), quanto maior a complexidade das atribuições e responsabilidades, maior deve ser o percentual de desenvolvimento não formal. $\mathrm{O}$ autor considera que complexidade demanda mais o uso diversificado do repertório de conhecimentos e experiências e menos o uso de novos repertórios, havendo a tendência de concentração no desenvolvimento de articulação do próprio repertório do indivíduo com o contexto no qual se insere. Com isso, as ações de desenvolvimento devem estimular o uso diferenciado do patrimônio de conhecimento que o indivíduo possui. O Esquema 2 mostra a estrutura das ações de desenvolvimento:

Esquema 2 - Estrutura das ações de desenvolvimento

SISTEMA

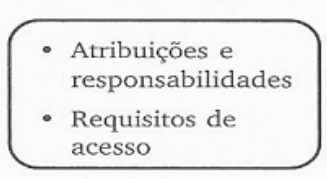

PORTFÓLIO DE AÇÕES DE DESENVOLVIMENTO

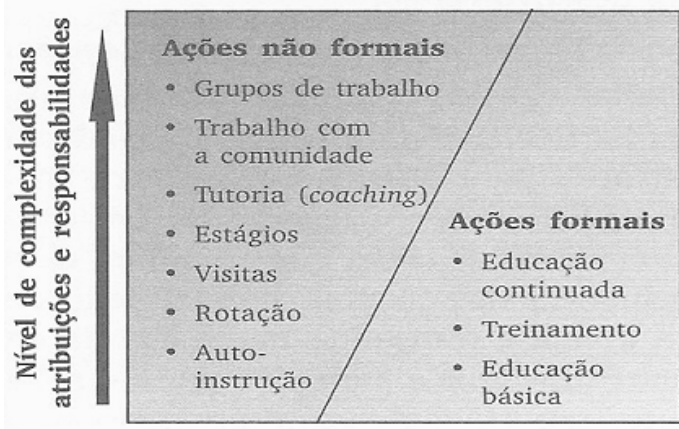

Fonte: Dutra (2008).

Para Dutra (2008), as ações de desenvolvimento precisam ser definidas com base nas necessidades de cada indivíduo e na premissa de ajudar a pessoa a 
mobilizar pontos fortes para se desenvolver, sendo possível ajudar os sujeitos a se desenvolverem por si mesmos. Com isso, as características individuais são valorizadas, a individualidade é preservada e é criado maior comprometimento com o próprio desenvolvimento.

Esse caráter pessoal e individualizado das ações de desenvolvimento está alinhado à perspectiva socioconstrutivista que também reconhece que as pessoas aprendem fazendo, descobrindo e compartilhando, em uma ação formal ou informal (COOPER; BASSON; SCHAAP, 2006). Tal constatação reforça os achados de Jain e Anjuman (2013), que indicam que o próprio local de trabalho, e não a sala de aula, é o lugar ideal para desenvolver, de forma hands-on, as soft skills.

Em estudo fenomenográfico, os participantes apontaram a experiência baseada na prática como a preferida para o desenvolvimento de suas competências (BAILEY, 2015). Segundo a experiência vivenciada pelos participantes, o desenvolvimento é uma característica da prática do dia a dia (BAILEY, 2015), o que reforça a existência, ou a inevitabilidade, e a importância da aprendizagem informal.

Integrado à perspectiva que indica a experiência como uma importante forma de desenvolver competências, Kempster e Parry (2012) estudaram o papel da observação nesse processo e destacam a importância das dinâmicas de atenção, acesso, motivação e comparação social com pessoas significativas, como propulsoras da aprendizagem pela observação. Essas "pessoas significativas" representam o papel de modelo e, segundo Warhurst (2011), as lições aprendidas com esses modelos estão relacionadas a valores, atitudes e ética.

\section{METODOLOGIA}

Trata-se de um estudo de caso com abordagem qualitativa, a partir de um caso empírico. $\mathrm{O}$ estudo de caso permite uma investigação que preserva as características holísticas e significativas dos eventos da vida real - como ciclos de vida individuais, processos organizacionais e administrativos, mudanças ocorridas em regiões humanas, relações internacionais e maturação de alguns setores (YIN, 1988). No presente estudo, buscou-se entender e circunstanciar os fatores intervenientes no processo de desenvolvimento de competências de gestão na Unidade de Serviços Compartilhados de uma empresa do setor de energia. A opção por essa empresa ocorreu pelo fato de ser uma organização que conta com um CSC bem estruturado e que também oferece um programa de formação para os seus futuros gestores, com 
foco no desenvolvimento das competências gerenciais - o que representa um campo particular para o estudo proposto, uma vez que possui um grupo de empregados que passou por um programa de formação, vivenciando uma experiência formal de desenvolvimento, como preparação para a gestão de Centros de Serviços Compartilhados, especificamente.

Desse conjunto de empregados - 45 empregados que estavam no banco de Potenciais Gerentes na Unidade de Serviços Compartilhados da empresa estudada -, abordaram-se 14 sujeitos. As entrevistas ocorreram na cidade do Rio de Janeiro, entre setembro e dezembro de 2012. A escolha dos entrevistados ocorreu de acordo com a disponibilidade de cada sujeito e conveniência do estudo para que houvesse representação de diversas carreiras (níveis técnico e superior), com diferentes gêneros, idades e tempo de companhia, até o momento em que ocorresse a saturação teórica, sendo coerente com Eisenhardt (1983), que propõe que o pesquisador deve parar de incluir novos casos quando a saturação teórica é alcançada, ou seja, quando novos conhecimentos incrementais são mínimos. O Quadro 3 apresenta, de forma panorâmica, a descrição dos entrevistados.

Quadro 3 - Descrição geral dos entrevistados

\begin{tabular}{|l|l|l|l|l|}
\hline Entrevistado & Gênero & $\begin{array}{l}\text { Carreira na Com- } \\
\text { panhia }\end{array}$ & $\begin{array}{l}\text { Faixa de } \\
\text { idade } \\
\text { (anos) }\end{array}$ & $\begin{array}{l}\text { Faixa de tempo } \\
\text { na Companhia } \\
\text { (anos })\end{array}$ \\
\hline Entrevistado 1 & Feminino & Administrador & $30-40$ & $5-10$ \\
\hline Entrevistado 2 & Feminino & Administrador & $40-50$ & $<5$ \\
\hline Entrevistado 3 & Feminino & Bibliotecário & $30-40$ & $5-10$ \\
\hline Entrevistado 4 & Masculino & $\begin{array}{l}\text { Técnico de Admi- } \\
\text { nistração e Controle }\end{array}$ & $40-50$ & $10-30$ \\
\hline Entrevistado 5 & Feminino & Assistente Social & $40-50$ & $5-10$ \\
\hline Entrevistado 6 & Feminino & $\begin{array}{l}\text { Técnico de Admi- } \\
\text { nistração e Controle }\end{array}$ & $>50$ & $>30$ \\
\hline Entrevistado 7 & Feminino & Administrador & $<30$ & $<5$ \\
\hline Entrevistado 8 & Masculino & Administrador & $30-40$ & $5-10$ \\
\hline Entrevistado 9 & Feminino & Medico do Trabalho & $30-40$ & $<5$ \\
\hline Entrevistado 10 & Feminino & $\begin{array}{l}\text { Enfermeiro do } \\
\text { Trabalho }\end{array}$ & $30-40$ & $<5$ \\
\hline Entrevistado 11 & Masculino & Engenheiro Civil & $30-40$ & $<5$ \\
\hline Entrevistado 12 & Masculino & $\begin{array}{l}\text { Técnico de Manu- } \\
\text { tenção }\end{array}$ & $<30$ & $10-30$ \\
\hline Entrevistado 13 & Masculino & Administrador & $30-40$ & $<5$ \\
\hline Entrevistado 14 & Masculino & $\begin{array}{l}\text { Técnico de Manu- } \\
\text { tenção }\end{array}$ & $30-40$ & $5-10$ \\
\hline
\end{tabular}

Fonte: os autores. 
Conforme pode ser vislumbrado no perfil dos entrevistados, julga-se ter atendido aos critérios de seleção sugeridos por Rubin e Rubin (1995), visto que os sujeitos selecionados conhecem a arena cultural ou a situação/experiência a ser estudada; têm vontade de falar; e; têm diferentes perspectivas.

O principal meio de coleta de dados adotado foi a entrevista semiestruturada. Esse procedimento permitiu obter percepções diferentes sobre os mesmos temas e questões, sem impedir que novos aspectos e considerações surgissem no decorrer das entrevistas. As entrevistas, que duraram 35 minutos em média, foram gravadas, transcritas e submetidas à análise de conteúdo. Para Gomes (1994), podem-se destacar duas funções na aplicação da análise de conteúdo: a primeira refere-se à verificação de questões, na qual, por meio da análise de conteúdo, é possível encontrar respostas para as questões formuladas, e também confirmar ou não as afirmações estabelecidas antes do trabalho de investigação; e a segunda diz respeito à descoberta do que está por trás dos conteúdos manifestos, indo além das aparências do que está sendo comunicado. Dessa forma, os depoimentos coletados foram submetidos a um processo de categorização que permitiu a comparação entre as distintas percepções dos entrevistados sobre o conteúdo de cada categoria estabelecida pelo agrupamento temático realizado a partir das próprias entrevistas (FLICK, 2009). Além da realização das entrevistas, buscou-se a triangulação dos dados (YIN, 1988), por meio da observação direta e da análise de documentos da empresa sobre gestão de competências e sobre o Programa de Desenvolvimento Gerencial.

\section{ANÁLISE E DISCUSSÃO DOS RESULTADOS}

O estudo foi realizado em uma companhia brasileira que atualmente apresenta produtos e serviços diversos, identificada no mercado como uma empresa de energia integrada. Essa empresa implantou, em novembro de 2000, a sua Unidade de Serviços Compartilhados, tendo a centralização e a padronização das atividades administrativas como a tônica para a criação dessa Unidade.

A estrutura de Serviços Compartilhados da empresa em estudo forma uma unidade integrada que atua na prestação de serviços administrativos e de suporte para atender às necessidades dessa empresa, oferecendo serviços de biblioteca, pessoal, assistência multidisciplinar em saúde, contratação de bens e serviços, infraestrutura, administração predial, comunicação empresarial, implementação de projetos de 
escritórios e segurança, meio ambiente e saúde (SMS). Possui uma estrutura central localizada no Rio de Janeiro e cinco regionais.

A empresa conta com um Programa de Desenvolvimento Gerencial para resguardar a companhia da descontinuidade de liderança, por meio da identificação, do desenvolvimento em gestão e da adequada alocação de empregados na carreira gerencial. As etapas do Programa de potenciais gerentes perpassam pela análise e pela indicação dos candidatos para posterior aprovação de uma comissão constituída para esse fim. Em seguida, inicia-se o processo de desenvolvimento em gestão. A participação do Programa não garante a designação do participante para uma posição de gestão. Havendo uma oportunidade para a função gerencial, verifica-se a adequação entre o perfil da vaga e o do potencial gerente e analisa-se a possibilidade de designação gerencial.

O estudo apoiou-se em categorias estruturadas a partir de eixos temáticos identificados na análise dos resultados encontrados em campo. Dessa forma, nesta seção serão apresentadas as análises nas categorias a respeito do entendimento de Serviços Compartilhados e das Competências Gerenciais Requeridas e acerca das percepções sobre a Formação de Competências Gerenciais.

Vale ressaltar que as três categorias de análise apresentam uma relação de dependência, como mostra o Esquema 3.

Esquema 3 - Relação de dependência entre as categorias de análise

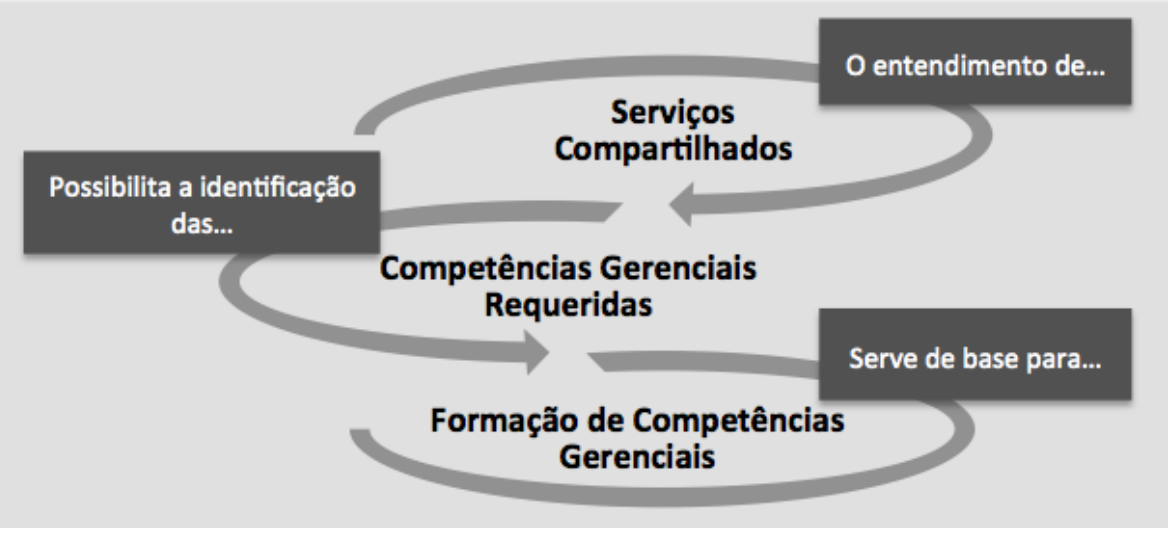

Fonte: os autores.

Apesar dessa relação de dependência, a análise das categorias será apresentada separadamente. 


\section{1 SERVIÇOS COMPARTILHADOS}

Nesta seção, buscou-se avaliar o entendimento dos entrevistados sobre a estrutura de serviços compartilhados. Foi possível perceber que todos os entrevistados souberam identificar e conceituar as características e os objetivos de sua unidade. Tal achado pode sugerir um alinhamento com o modelo de gestão e as estratégias, ponto importante para um gestor. Os entrevistados, em linha com Bergeron (2003), Schulman et al. (2001), Kaplan (2000), Shah (1998) e Quinn, Cooke e Kris (2000), souberam conceituar, de diversas formas, a Unidade de Serviços Compartilhados como aquela que presta serviços de suporte e administrativos para as demais unidades, para oportunizar que as outras áreas tenham foco específico em seus próprios objetivos organizacionais ou atividade-fim da empresa. Além disso, a questão abordada pelos entrevistados sobre a otimização e a redução de custo encontra paralelo em Shah (1998), que atenta para a busca da maximização da utilização de recursos.

Pode-se verificar a percepção de que a unidade de Serviços Compartilhados ainda não está totalmente integrada, estando em processo de mudança para que seus serviços sejam de fato centralizados. Conforme modelos de Centros de Serviços Compartilhados apresentados por Quinn, Cooke e Kris (2000), a empresa estudada tem o modelo MarketPlace, no qual a utilização dos Serviços Compartilhados não é compulsória e há o repasse de custos para os clientes internos. A percepção sobre esse tipo de unidade, assim como o que é esperado de um gestor de Serviços Compartilhados, é um norteador na busca dos potenciais gestores pelo seu desenvolvimento gerencial, já que os entrevistados têm expectativas de ser convidados para uma posição de liderança dentro dessa estrutura.

\section{2 COMPETÊNCIAS GERENCIAIS REQUERIDAS}

Nesta seção, buscou-se avaliar a percepção dos entrevistados no que se refere às competências gerenciais requeridas para o desempenho gerencial.

Antes de analisar os fatores intervenientes na formação de competências, é importante verificar quais competências são importantes para o desempenho gerencial, principalmente no contexto da Unidade de Serviços Compartilhados. Diversas competências foram citadas pelos entrevistados como prioritárias para os gestores. Para melhor visualização, as competências citadas foram agrupadas em 
quatro categorias. Os grupos 1, 2 e 3 apresentam as competências de acordo com o entendimento do papel gerencial estabelecido pela empresa estudada: gerir pessoas, processos e negócios (definição institucional). Por sua vez, o grupo 4 corresponde àquelas que não puderam ser incluídas especificamente em algum dos outros grupos, por se tratarem de competências transversais, que devem "acompanhar" as competências classificadas nos outros três grupos. O Quadro 4 apresenta os quatro grupos de competências.

Quadro 4 - Competências reveladas pelos entrevistados

\begin{tabular}{|c|c|c|c|}
\hline $\begin{array}{l}\text { Grupo } 1 \text { - Gestão } \\
\text { de Pessoas }\end{array}$ & $\begin{array}{l}\text { Grupo } 2 \text { - Gestão } \\
\text { de Processos }\end{array}$ & $\begin{array}{l}\text { Grupo } 3 \text { - Gestão } \\
\text { de Negócios }\end{array}$ & $\begin{array}{l}\text { Grupo } 4 \text { - Compe- } \\
\text { tências Transversais } \\
\text { de Gestão }\end{array}$ \\
\hline $\begin{array}{ll}\text { - } & \text { Capacidade } \\
\text { de gestão de } \\
\text { pessoas } \\
\text { - } & \text { Liderança } \\
\text { - } & \text { Empatia } \\
\text { - Trabalho em } \\
\text { - equipe } \\
\text { Capacidade de } \\
\text { relacionamen- } \\
\text { to interpessoal }\end{array}$ & $\begin{array}{ll}\text { - } & \text { Capacidade } \\
\text { de gestão de } \\
\text { processos } \\
\text { - } \quad \text { Capacidade de } \\
\text { planejamento } \\
\text { - } \quad \text { Capacidade de } \\
\text { organização } \\
\text { - } \quad \text { Objetividade } \\
\text { - Capacidade } \\
\text { de redução } \\
\text { de custos e } \\
\text { otimização }\end{array}$ & $\begin{array}{ll}\text { - } & \text { Capacidade } \\
\text { de gestão de } \\
\text { negócios } \\
\text { - } \quad \text { Foco no } \\
\text { cliente } \\
\text { - } \quad \text { Empreendedo- } \\
\text { rismo } \\
\text { - Capacidade de } \\
\text { obter resulta- } \\
\text { dos organiza- } \\
\text { cionais } \\
\text { Capacidade } \\
\text { de articulação } \\
\text { política }\end{array}$ & $\begin{array}{ll}\text { - } & \text { Capacidade de } \\
\text { - } & \text { negociação } \\
& \text { decisão } \\
\text { - } & \text { Flexibilidade } \\
\text { - } & \text { Criatividade } \\
\text { - } & \text { Inovação } \\
\text { - } & \text { Visão sistêmica } \\
\text { - } & \text { Capacidade de } \\
& \text { agir de forma } \\
\text { - } & \text { proativa } \\
\text { - } & \text { Resiliência } \\
\text { - } & \text { Atençãão a } \\
& \text { detalhes } \\
\text { - } & \text { Iniciativa }\end{array}$ \\
\hline
\end{tabular}

Fonte: os autores.

O agrupamento apresentado considerou o contexto dos entrevistados no programa de formação, com foco nas dimensões Gestão de Pessoas, Gestão de Negócios e Gestão de Processos, em linha com as áreas de conhecimentos propostas por Motta (2002). A primeira delas é a da estratégia (análogo com Gestão de Negócios), relativa à capacidade de análise de fatores externos e internos para o melhor uso de recursos escassos no alcance de objetivos e para o conhecimento de planejamento estratégico. A segunda área é a da racionalidade administrativa (correlato com Gestão de Processos), referente à capacidade de compreensão de técnicas gerenciais e ao conhecimento de técnicas de programação, orçamentação e sistemas de informação. A terceira área é a de liderança e habilidades interpessoais (congruente com Gestão de Pessoas). A última área, a quarta, é relativa ao processo decisório, que abrange a capacidade de compreender processos organizacionais 
de decisão e conhecimentos sobre comportamento administrativo, dinâmica organizacional e processos de inovação e mudança.

Em relação às competências gerenciais para outras áreas distintas da área de Serviços Compartilhados, houve entendimentos diferentes entre os entrevistados. Alguns entendem que as competências gerenciais são as mesmas para qualquer gerente ou que apenas algumas são básicas a todos. Outra parte dos entrevistados indicou que, de acordo com o contexto, o tipo de atividade ou a unidade, as competências prioritárias aos gerentes são distintas. Uma diferença encontrada entre as competências requeridas para os gestores de Serviços Compartilhados e para os gestores das demais áreas é o conhecimento técnico desses gerentes. Segundo os entrevistados, enquanto os gestores de Serviços Compartilhados devem ter maior competência em gestão de pessoas para a prestação dos serviços com foco nos clientes, os gestores das demais unidades devem ter o conhecimento técnico mais apurado. As competências gerenciais citadas por Mintzberg (1973), Cockerill (1994) e Picarelli Filho (1997) foram abordadas também pelos entrevistados, entretanto, com nomes de atributos, habilidades e categorias diferentes.

Não ficou perceptível no discurso dos entrevistados a importância de algumas competências relacionadas a aspectos da contemporaneidade identificadas por Closs e Antonello (2014) e, tampouco, as relacionadas às inteligências emocional e social ou as soft skills (BOYATZIS, 2011; THORY, 2013; JAIN; ANJUMAN, 2013; CHROBOTMASON; LESLIE, 2012). Alguns exemplos de competências que não foram identificados nas entrevistas são: entendimento e aceitação de outros valores; compreensão de semelhanças e diferenças organizacionais em contextos culturais distintos; estabelecimento de limites entre a vida pessoal e a profissional. Essa lacuna leva à suposição de que os entrevistados têm um conceito de competência mais alinhado à visão clássica da função gerencial: planejar, organizar, dirigir e controlar (LAND; SILVA, 2011).

\section{3 FORMAÇÃO DE COMPETÊNCIAS GERENCIAIS}

Esta seção representa a percepção dos entrevistados acerca das questões que se referem tanto à formação de competências gerenciais quanto aos fatores intervenientes desse processo. 


\section{3. 1 Formas de desenvolvimento}

As diversas formas de desenvolvimento de competências, informais e formais, foram citadas pelos entrevistados. Entretanto, na percepção desses sujeitos, as formas de aprendizagem mais importantes são: os treinamentos, a articulação entre a teoria e a prática, o compartilhamento de experiências com os gestores/ lideranças atuais, a possibilidade de substituição gerencial e o feedback.

Os treinamentos são uma das formas de aprendizagem formais mais utilizadas nas empresas e foi a mais citada pelos entrevistados. Entretanto, para Ruas e Comini (2007), os treinamentos tendem a gerar um gap, já que não se concretizam as expectativas de desenvolver competências de forma quase automática. De toda forma, os entrevistados demonstraram que a aprendizagem em treinamentos é relevante para eles.

Houve algumas considerações em relação às propostas de treinamentos. Para esses entrevistados, existe a preocupação de os treinamentos atrapalharem a rotina no trabalho em razão da carga horária excessiva ou do agendamento do curso em período de grande movimento em suas atividades profissionais, o que gera estresse e preocupação. Apesar de o treinamento ser um dos principais mecanismos de desenvolvimento de competências citados pelos sujeitos, somente esse mecanismo não é suficiente, já que está mais focado no "acúmulo de conhecimentos", sendo mais teórico, tendo que haver a constante articulação entre a teoria e a prática, inclusive para a sedimentação dos conhecimentos. Essa constatação encontra respaldo em Dutra (2008), que assevera que a competência não é um estado ou conhecimento que se tem, ou um resultado de treinamento, mas, sim, colocar em prática o que se sabe em determinado âmbito, influenciada geralmente pelas relações de trabalho, pela cultura da organização, pelas contingências e pelas diversas limitações. Essa valorização por práticas, experiências e vivências é consonante com Dutra (2008) e Ouweneel et al. (2009), que também asseveram que quanto maior a complexidade das atribuições e responsabilidades, maior deve ser o percentual das ações de desenvolvimento não formais. No conteúdo das entrevistas, houve mais ocorrências e priorização de ações de desenvolvimento estruturadas por meio da atuação no próprio trabalho e ligadas à atuação profissional.

Além disso, Brown e Duguid (2000) ensinam que a visão construtivista preconiza que instruções formais sobre como fazer o trabalho são inadequadas, na medida em que as informações de como executar efetivamente não estão escritas e são obtidas por trocas informais entre pessoas experientes e menos experientes. A proposta central dessa perspectiva é que grande parte do conhecimento organizacional 
fundamental não está somente no papel ou nas mentes dos indivíduos, mas dentro da organização como um todo.

Uma das propostas apresentadas pelos entrevistados para envolver a prática em sua formação é a oportunidade de substituição do gestor atual, sendo vista como importante para o desenvolvimento de competências gerenciais, pois nesse momento o indivíduo poderá ter uma percepção mais aguçada de quais são os desafios e poderá assumir de fato parte das responsabilidades de um gerente, inclusive na utilização de sistemas e práticas gerenciais importantes no cotidiano do gestor. Para Le Boterf (1999), a substituição gerencial está agrupada nas situações cuja finalidade principal e tradicional é de formação/treinamento.

As considerações dos entrevistados encontram respaldo teórico nas definições de Bastos et al. (2004), Cooper, Basson e Schaap (2006), Jain e Anjuman (2013), Bailey (2015) e Kempster e Parry (2012), que defendem que a aprendizagem individual ocorre por meio da experiência, da observação e da aptidão que o ser humano apresenta para pensar e analisar determinada circunstância, promovendo estruturas cognitivas, modelos interpretativos e hábitos de trabalho.

Os entrevistados demonstraram que tanto o indivíduo em desenvolvimento quanto suas lideranças devem estar envolvidos no processo de formação de futuros gestores. Em consonância com os relatos, Dutra (2008) diz que a cumplicidade (do indivíduo e da chefia) aumenta as chances de sucesso, o qual pode ser mensurado pelas mudanças ou falta delas na entrega da pessoa após as ações de desenvolvimento.

Entre as principais formas de aprendizagem e desenvolvimento, o fato de existirem feedbacks durante o exercício de suas atividades e no decorrer do processo de formação de competências é citado como relevante. Entende-se que é a partir desses retornos e conversas com os gestores ou com a equipe que o possível futuro gerente obtém informações sobre o alinhamento de suas posturas e ações com os objetivos organizacionais e de gestão. Além disso, também são avaliados para que saibam se sua formação gerencial está de fato ocorrendo. Para Antonello (2004), o incremento do autoconhecimento requer feedback quanto à competência ou à incompetência demonstrada pelo indivíduo, pois a competência é determinada pela imagem que a pessoa tem de si (autoimagem) e pela imagem que os outros formam dela. Assim, a forma como suas ações são percebidas e recebidas por outros, proporciona-lhe um feedback que possibilitará que corrija e complemente a sua autoimagem.

A maior parte dos entrevistados demonstrou interesse em avaliações constantes, já que está em um processo de formação de competências e quer saber se está no caminho correto e efetivo para tal objetivo. 
Esses achados corroboram os de Ellström e Ellström (2014), que ressaltam a importância dos gestores “apoiadores”, em contraste com os "não apoiadores”, para os resultados dos treinamentos realizados por suas equipes.

Com menor ocorrência, outras formas de desenvolvimento de competências também foram citadas: delegação de atividades, experiências (dentro e fora da companhia), rodízio de atividades, grupo de trabalhos, leituras e autorreflexão.

Entretanto, percebe-se que os entrevistados priorizam a ação, a vivência em si, sem relatar a importância da reflexão sobre a ação - antes, durante ou depois da experiência -, como preconiza Antonello (2007). A reflexão realizada nos feedbacks parece limitar-se à avaliação do status de desenvolvimento das competências - se há gaps -, mas, em momento algum, parece uma reflexão sobre a ação que caracterize a aprendizagem pela experiência.

Com o objetivo de sintetizar as revelações do campo acerca da formação de competências, propõe-se uma articulação, apresentada no Quadro 5, entre as formas de desenvolvimento de competências analisadas nas falas dos sujeitos entrevistados e aquelas propostas por Cheetham e Chivers (2001) e Antonello (2004).

Quadro 5 - Integração das formas de aprendizagem

\begin{tabular}{|c|c|c|}
\hline $\begin{array}{l}\text { Cheetham e Chivers } \\
(2001)\end{array}$ & Antonello (2004) & $\begin{array}{l}\text { Revelações do campo } \\
(2012)\end{array}$ \\
\hline Atitudes e ações (informais) & Formas de aprendizagem & Formação de competências \\
\hline Prática e repetição & \multirow{3}{*}{ Experienciar } & Prática \\
\hline \multirow{2}{*}{$\begin{array}{l}\text { Atividades de mais esforço } \\
\text { ou tensão }\end{array}$} & & Delegação de atividades \\
\hline & & Substituição gerencial \\
\hline \multirow{2}{*}{$\begin{array}{l}\text { Mudança/Alteração de } \\
\text { perspectiva }\end{array}$} & \multirow{2}{*}{ Mudança de perspectiva } & \\
\hline & & Rodízio \\
\hline Observação e Cópia & Observação (Modelos) & \multirow{2}{*}{$\begin{array}{l}\text { Compartilhamento de ex- } \\
\text { periências com os gestores/ } \\
\text { lideranças atuais }\end{array}$} \\
\hline Mentoring & $\begin{array}{l}\text { Mentoria (mentoring) e } \\
\text { Tutoria (coaching) }\end{array}$ & \\
\hline Avaliação (feedback) & Feedback & Feedback \\
\hline $\begin{array}{l}\text { Transferência de ocupações } \\
\text { extraprofissionais }\end{array}$ & $\begin{array}{l}\text { Experiência anterior e } \\
\text { transferência extraprofis- } \\
\text { sional }\end{array}$ & $\begin{array}{l}\text { Experiência (dentro e fora } \\
\text { da Companhia) }\end{array}$ \\
\hline Articulação & $\begin{array}{l}\text { Aprendizagem pela articu- } \\
\text { lação entre teoria e prática }\end{array}$ & $\begin{array}{l}\text { Articulação entre a teoria e } \\
\text { a prática }\end{array}$ \\
\hline Colaboração & $\begin{array}{l}\text { Interação e colaboração } \\
\text { (em grupo) }\end{array}$ & Grupos de trabalhos \\
\hline
\end{tabular}




\begin{tabular}{|l|l|l|}
\hline Reflexão & Reflexão & \multirow{2}{*}{ Autorreflexão } \\
\cline { 1 - 2 }- & $\begin{array}{l}\text { Autoanálise (Autoconheci- } \\
\text { mento) }\end{array}$ & Treinamento \\
\hline- & Treinamentos & $\begin{array}{l}\text { Identificação de competên- } \\
\text { cias e gaps }\end{array}$ \\
\hline- & - & - \\
\hline Absorção inconsciente & - & - \\
\hline $\begin{array}{l}\text { Uso de dispositivos men- } \\
\text { tais }\end{array}$ & - & $\begin{array}{l}\text { Informal (no trabalho e no } \\
\text { curso de Pós) }\end{array}$ \\
\hline- & - \\
\hline
\end{tabular}

Fonte: adaptado de Cheetham e Chivers (2001) e Antonello (2004).

\section{3. 2 Fatores intervenientes}

Quando questionados sobre o que poderia facilitar a formação de competências gerenciais, além das formas de aprendizagem e desenvolvimento já abordadas, os entrevistados indicaram outros facilitadores, que dizem respeito à disposição - tanto do potencial gestor quanto da liderança atual - e ao interesse no desenvolvimento ou comprometimento com o trabalho. A equipe também foi revelada tendo papel importante, pois deve permitir e aceitar que o sujeito em desenvolvimento possa treinar, ter experiências de gestão com eles, oferecendo um ambiente favorável ao desenvolvimento de competências, ou seja, um tipo de suporte. Para facilitar tal desenvolvimento, também se deve estimular a independência do empregado e, nas atividades-chave ou naquelas em que ele tenha mais dificuldade, proporcionar que crie um hábito na execução.

Outro fator correlato que pode facilitar esse desenvolvimento é a criação de novas oportunidades de trabalho para o empregado, possibilitando que se tenha uma sensação de crescimento profissional e reconhecimento de seus resultados. Assim, o indivíduo terá motivação tanto no trabalho quanto no seu próprio desenvolvimento. Em relação aos entraves no processo de formação de competências, foi mencionado diversas vezes que o oposto das instâncias consideradas facilitadoras poderia surgir como um empecilho no desenvolvimento pleno dos empregados: falta de colaboração do líder, resistência da equipe, falta de comunicação apropriada e ambiente desfavorável.

Algo recorrente na fala dos sujeitos entrevistados foi a questão de cair na rotina, pois o processo de desenvolvimento requer tempo e dedicação, mas a rotina diária e o tempo dispensado na execução de tarefas mais operacionais dificultam o 
processo de formação de competências. Essa aparente dissociação entre a rotina diária e o processo de desenvolvimento leva a concluir que os entrevistados talvez não tenham desenvolvido a metacompetência "aprender a aprender" (GODOY; D’AMELIO, 2012), o que lhes proporcionaria o instrumental necessário para transformar sua prática profissional em oportunidade de criação de saber, a partir da experiência, como propõe Le Boterf (2003). Colocar intenção (ANTONELLO, 2007) no aprender pela execução das tarefas poderia levá-los a não cair na rotina. Dessa forma, a metacompetência "aprender a aprender" pode ser considerada um fator interveniente importante na formação das competências gerenciais, pelo seu poder em potencializar as aprendizagens informais - tão valorizadas nos trabalhos teóricos apresentados neste artigo (DUTRA, 2008; OUWENEEL et al., 2009; BROWN; DUGUID, 2000; BAILEY, 2015; COOPER; BASSON; SCHAAP, 2006; JAIN; ANJUMAN, 2013; CHEETHAM; CHIVERS, 2001; ANTONELLO, 2007).

O gerente aparece como outro elemento importante nesse processo de formação e pode ter um papel de facilitador ou dificultador. Nos relatos dos entrevistados, houve questões como assédio moral, feedback deficiente, não observação de meritocracia e situações nas quais o gerente boicota o desenvolvimento do empregado por temer o crescimento profissional deste - o que se pode relacionar ao "gerente não apoiador" apresentado por Ellström e Ellström (2014).

\section{CONCLUSÃO}

Julga-se que o estudo atingiu o objetivo de investigar os fatores intervenientes na formação de competências gerenciais.

Uma primeira constatação relevante, em relação ao conjunto de Competências Gerenciais, foi a revelação, pelos entrevistados, de um novo grupo de competências. Ao agrupamento de competências institucionalmente proposto - Gestão de Pessoas, Gestão de Processos e Gestão de Negócios - a análise das entrevistas permitiu agregar o grupo das competências transversais. Cabe investigar se essa descoberta é consequência do fato de que os sujeitos abordados são futuros gestores e, à época da pesquisa, já se encontravam em processo de formação gerencial. Será possível afirmar que a percepção dessas novas competências, não abordadas institucionalmente pela empresa, já representa um resultado do Programa de Desenvolvimento Gerencial? 
Outra descoberta importante diz respeito ao fato de que a formação de competências gerenciais independe da área da empresa em que as competências de gestão serão aplicadas. Ou seja, na percepção dos entrevistados, investir em um programa específico para a formação de potenciais gestores do CSC não demonstrou ser essencial para o sucesso gerencial da área.

Ainda em relação ao processo de formação, não foi possível constatar um único caminho para o desenvolvimento de competências gerenciais. Verificou-se que a ideia de navegação profissional é coerente com a realidade desses indivíduos, que percebem a importância de haver um mapa de oportunidades para o desenvolvimento gerencial, o qual pode ser adaptado a diversas situações de aprendizagem.

Uma contribuição importante para futuros programas da empresa diz respeito à valorização e ao desejo dos gestores em formação por atividades práticas, assim como vivências das competências gerenciais, que seriam viabilizadas pelos processos de aprendizagem informais. Em razão do fato de o potencial gerente estar em processo de capacitação para atribuições e responsabilidades de maior complexidade, ele precisa melhorar sua capacidade de articular seu repertório de conhecimentos com o contexto real.

Apesar da observação da valorização da aprendizagem por meio das práticas de trabalho, foi declarado que deveria haver a combinação da prática com outras formas de desenvolvimento. Ao ser verificada a importância atribuída à contribuição da aprendizagem informal para o desenvolvimento de competências, emergiram as limitações das ações formais de aprendizagem propostas pelo Programa de Desenvolvimento Gerencial.

Essa diversidade encontrada nos achados deste estudo representa uma importante contribuição teórica para o campo de formação de Competência Gerencial, pois desmistifica paradigmas de estudos anteriores que classificam o formal como ruim e o informal como bom, ou vice-versa (MANUTI et al., 2015) e traz o entendimento de que tanto as ações formais quanto as informais podem gerar aprendizado desenvolvimento de competências, dependendo do contexto, do indivíduo, do grupo e das competências a serem desenvolvidas. Ou seja, como indica Manuti et al. (2015, p. 12), não deve haver uma “[...] abordagem one-size-fitsall (tamanho único) para a aprendizagem no trabalho."

Qualquer iniciativa relacionada à capacitação de futuros gestores ou à sucessão gerencial foi avaliada como positiva, considerando que, para que seja efetiva, é necessário que haja mais possibilidade de desenvolvimentos práticos. Por outro lado, aqueles sujeitos que foram escolhidos para o Programa em análise 
já detinham parte das competências e perfil para uma posição de gestão naquela empresa. Com isso, o Programa de Desenvolvimento Gerencial demonstra ter o objetivo de compor um banco para a consulta e uma possibilidade de alavancar o desenvolvimento desses empregados.

Destacou-se a importância dos gerentes atuais no processo de desenvolvimento, já que esses atores serão aqueles que passarão sua expertise para os demais e poderão facilitar e propor atividades que auxiliem no desenvolvimento desses empregados. Além disso, nota-se que o processo de avaliação e feedback é importante no acompanhamento do desenvolvimento desses indivíduos e que são os gerentes atuais que realizam essa tarefa. Ficou também evidente que ainda é necessário criar meios de mensuração do desenvolvimento desses empregados que estão em formação gerencial.

Apesar do papel destacado dos gerentes atuais, a autonomia e a autodireção do futuro gestor em seu próprio processo de formação foram reveladas como fatores fundamentais para o desenvolvimento. A empresa, ao incluir determinado empregado no Programa de Desenvolvimento Gerencial, já demonstra que identifica nele traços de características e competências para ser um futuro gerente. De certa forma, já é esperado que o empregado busque elementos que possam favorecer o seu desenvolvimento, sendo ativo no seu processo de aprendizagem.

Em razão das delimitações estabelecidas para este estudo e da limitação do método utilizado, para trabalhos futuros, sugere-se a realização de um estudo que envolva também as atuais lideranças e a equipe de RH que desenvolveu e operacionaliza o Programa. Além disso, seria interessante realizar o estudo com empregados das diversas unidades da empresa, a fim de investigar similaridades ou divergências de percepções encontradas nesta pesquisa. Também se sugere para trabalhos futuros um estudo que possa verificar a efetividade do Programa de Desenvolvimento Gerencial.

\section{REFERÊNCIAS}

ABBAD, G. S.; BORGES-ANDRADE, J. E. Aprendizagem humana em organizações de trabalho. In: ZANELLI, J. C.; BORGES-ANDRADE, J. E.; BASTOS, A. V. B. (Ed.). Psicologia, organizações e trabalho no Brasil. Porto Alegre: Artmed, 2004.

ANTONELLO, C. S. Aprendizagem na ação revisitada e sua relação com a noção de competência. Aletheia, Ulbra, v. 26, p. 146-167, 2007. 
ANTONELLO, C. S. As formas de aprendizagem utilizadas por gestores no desenvolvimento de competências. In: ENANPAD, 28., 2004, Curitiba. Anais... Curitiba: [s.n.], 2004.

ANTONELLO, C. S.; RUAS, R. Formação gerencial: pós-graduação lato sensu e o papel das comunidades de prática. Revista de Administração Contemporânea, Curitiba, v. 9, n. 2, abr./jun. 2005.

BAILEY, M. Professional development of HR practitioners - a phenomenographic study. European Journal of Training and Development, v. 39, n. 3, p. 220$238,2015$.

BASTOS, A. V. B. et al. Aprendizagem organizacional versus organizações que aprendem: características e desafios que cercam essas duas abordagens de pesquisa. RAUSP, Revista de Administração da USP, São Paulo, v. 39, n. 3, p. 220-230, 2004.

BERGERON, B. Essentials of shared services. New Jersey: John Wiley \& Sons, 2003.

BOYATZIS, R. E. Managerial and Leadership Competencies: A Behavioral Approach to Emotional, Social and Cognitive Intelligence. Vision, v. 15, n. 2, p. 91-100. 2011.

BROWN, J. S.; DUGUID, P. The social life of information. Boston: Harvard Businesses Scholl Press, 2000.

CHEETHAM, G.; CHIVERS, G. How professionals learn in practice: an investigation of informal learning amongst people working in professions. Journal of European Industrial Training, v. 25, n. 5, p. 248-292, 2001.

CHROBOT-MASON, D.; LESLIE, J. B. The Role of Multicultural Competence and Emotional Intelligence in Managing Diversity. The Psychologist-Manager Journal, v. 15, p. 219-236, 2012.

CLOSS, L. Q.; ANTONELLO, C. S. Aprendizagem de gestores no contexto das transformações contemporâneas. Revista de Ciências da Administração (CAD/ UFSC), v. 16, n. 39, p. 149-163, 2014.

COCKERILL, T. The kind of competence for rapid change. In: MABEY, C.;

ILES, P. (Org.). Managing learning. London: Open University, 1994. 
COOPER J.; BASSON, J.; SCHAAP, P. A Training Programme Based on the Principles of Social Constructivism and Focused on Developing People for the Future World of Work: An Evaluation. Human Resource Development International, v. 9, n. 4, p. 467-483, dez. 2006.

CROSBY, P. B. Liderança: a arte de tornar-se um executivo. São Paulo: Makron, MccGraw-Hill, 1991.

DUTRA, J. S. Competências: conceitos e instrumentos para a gestão de pessoas na empresa moderna. São Paulo: Atlas, 2008.

EISENHARDT, K. M. Building Theories From Case Study Research. Academy of Management Review, v. 14, n. 4, p. 532-550, 1989.

ELLSTRÖM, E.; ELLSTRÖM, P. Learning outcomes of a work-based training programme. European Journal of Training and Development, v. 38, n. 3, p. 180-197, 2014.

FLEURY, M. T. L.; FLEURY, A. Estratégias empresariais e formação de competências: um quebra-cabeça caleidoscópio da indústria brasileira. São Paulo: Atlas, 2004.

FLICK, U. Desenho da pesquisa qualitativa. Porto Alegre: Artmed, 2009.

GODOY, A. S.; D’AMELIO, M. Competências gerenciais desenvolvidas por profissionais de diferentes formações. Organizações \& Sociedade, Salvador, v. 19, n. 63, p. 621-639, out./dez. 2012.

GOMES, R. A análise de dados em pesquisa qualitativa. In: MINAYO, Maria Cecília de Souza. Pesquisa Social: teoria, método e criatividade. Petrópolis: Vozes, 1994.

JAIN, S.; ANJUMAN, A. S. S. Facilitating the Acquisition of Soft Skills Through Training. The IUP Journal of Soft Skills, v. 7, n. 2, 2013.

KAPLAN, R. S. Organização orientada para a estratégia: como as empresas que adotam o balanced scorecard prosperam no novo ambiente de negócios. Rio de Janeiro: Elsevier, 2000.

KEMPSTER, S.; PARRY, K. Exploring observational learning in leadership development for managers. Journal of Management Development, v. 33, n. 3, p. 164-181, 2014.

LAND, A. L.; SILVA, A. B. Compétence et navigation professionnelle. Paris: Les Editions d'Organisation, 1999. 
LAND, A. L.; SILVA, A. B. Desenvolvendo a competência dos profissionais. Porto Alegre: Bookman, 2003.

LAND, A. L.; SILVA, A. B. Fatores determinantes do pensamento complexo na prática gerencial em empresas varejistas. Revista Eletrônica de Estratégia e Negócios, Florianópolis, v. 4, n. 1, p. 19-41, jan./jun. 2011.

MAIMONE, F.; SINCLAIR, M. Dancing in the dark: creativity, knowledge creation and (emergent) organizational change. Journal of Organizational Change Management, v. 27, n. 2, p. 344-361, 2014.

MANFREDINI, V. A formação de líderes globais: um estudo de caso na General Motors do Brasil. Dissertação (Mestrado em Administração)Universidade Federal do Rio Grande do Sul, Porto Alegre, 2007.

MANUTI, A. et al. Formal and informal learning in the workplace: a research review. International Journal of Training and Development, v. 19, n. 1, 2015.

MATTOS, R. A. Desenvolvimento de Recursos Humanos e Mudança Organizacional. Rio de Janeiro: LTC/ANFUP, 1985.

MINTZBERG, H. The nature of managerial work. NewYork: Harper \& How, 1973.

MOTTA, P. R. Gestão contemporânea: a arte de ser dirigente. Rio de Janeiro: Record, 2002.

OUWENEEL, E. A. P. et al. How Task Characteristics and Social Support Relate to Managerial Learning: Empirical Evidence From Dutch Home Care. The Journal of Psychology, v. 143, n. 1, p. 28-44. 2009.

PARRY, S. B. Just what is a competency? Training, Minneapolis, p. 58-64, June 1998.

ROBBINS, S. P.; COULTER, M. Administração. Rio de Janeiro: PrenticeHall, 1998.

ROCHA, E. P.; SALLES, J. A. A. Competências e a gestão de pessoas. Revista de Administração CREUPI, São Paulo, v. 5, n. 9, jan./dez. 2005.

RUAS, R.; COMINI, G. M. Aprendizagem e desenvolvimento de competências: articulando teoria e prática em programas de pós-graduação em formação gerencial. Cadernos EBAPE.BR (FGV. On-line), p. 36-49, 2007. 
RUAS, R. L. Literatura, dramatização e formação gerencial: a apropriação de práticas teatrais ao desenvolvimento de competências gerenciais. Organizações e Sociedade, Salvador, v. 12, p. 121-142, 2005.

RUBIN, H. J.; RUBIN, I. S. Qualitative interviewing: The art of hearing data. Thousand Oaks: Sage Publications. 1995, 302 p.

SCHULMAN, D. S. et al. Shared services: adding value to the business units. New Jersey: John Wiley \& Sons, 2001.

SHAH, B. Shared Services: is it for you? Industrial Management, Atlanta, v. 4, n. 50, p. 4-8, set. 1998.

SHEEHAN, M. Developing managerial talent. European Journal of Training and Development, v. 36, n. 1, p. 66-68. 2012.

STREIT, C. L. Desenvolvimento de competências individuais comportamentais associadas à inovação na gestão: a contribuição da aprendizagem organizacional. Dissertação (Mestrado em Administração)Universidade Federal do Rio Grande do Sul, Porto Alegre, 2001.

THORY, K. Teaching managers to regulate their emotions better: insights from emotional intelligence training and work-based application. Human Resource Development International, v. 16, n. 1, p. 4-21, 2013.

WARHURST, R. Role modelling in manager development: learning that which cannot be taught. Journal of European Industrial Training, v. 35, n. 9, p. 874891, 2011.

YIN, R. Case study research: design and methods. Califórnia: Sage Publications. 1988.

ZARIFIAN, P. Objetivo competência: por uma nova lógica. São Paulo: Atlas, 2001. 


\section{Como citar este artigo:}

SANTOS, Murilo Rodrigues dos; ROCHA-PINTO, Sandra Regina;

$\mapsto$ GUIMARÃES, Maria Isabel Peixoto. Centros de Serviços Compartilhados:

$Z$ um estudo de caso sobre fatores intervenientes na formação de Competências

\& Gerenciais. RACE, Revista de Administração, Contabilidade e Economia.

Joaçaba: Ed. Unoesc, v. 14, n. 2, 505-536, maio/ago. 2015. Disponível em: < http:// editora.unoesc.edu.br/index.php/race >. Acesso em: dia/mês/ano.

Santos, M. R. dos, Rocha-Pinto, S. R. da, \& Guimarães, M. I. P. Centros de Serviços Compartilhados: um estudo de caso sobre fatores intervenientes \& na formação de Competências Gerenciais. RACE, Revista de Administração, Contabilidade e Economia, 14(2), 505-536. Recuperado em dia/mês/ano, de http:// editora.unoesc.edu.br/index.php/race 
